\title{
INDICADORES AMBIENTAIS: UM ESTUDO COMPARATIVO ENTRE EMPRESAS BRASILEIRAS E ESPANHOLAS
}

\author{
Ana Rita Pinheiro de Freitas \\ Mestranda em Administração e Controladoria pela Universidade Federal do Ceará - UFC \\ anarita1802@hotmail.com \\ Ariella Burali de Campos Kobal \\ Mestranda em Administração e Controladoria pela Universidade Federal do Ceará - UFC \\ ariellaburali@yahoo.com.br \\ Márcia Martins Mendes De Luca \\ Doutora em Contabilidade e Controladoria pela Universidade de São Paulo - USP \\ Professora do Programa de Pós-Graduação da Universidade Federal do Ceará - UFC \\ marciadeluca@ufc.br
}

Alessandra Carvalho de Vasconcelos

Doutora em Engenharia de Produção pela Universidade Federal de Santa Catarina - UFSC Professora do Programa de Pós-Graduação da Universidade Federal do Ceará - UFC alegallon@terra.com.br

\section{RESUMO}

Este estudo tem por objetivo comparar os indicadores ambientais utilizados pelas empresas brasileiras com aqueles empregados pelas empresas espanholas, a partir dos relatórios, segundo o modelo da Global Reporting Initiative (GRI), divulgados nos respectivos websites institucionais a partir de 2010. Para tanto, foram analisados os relatórios de sustentabilidade de 280 empresas dos dois países. Trata-se de uma pesquisa descritiva, de natureza quantitativa, adotando-se os procedimentos bibliográfico e documental. Os resultados mostram que as empresas brasileiras e espanholas, na totalidade dos indicadores evidenciados, apresentam comportamento similar, sendo mais evidenciados os itens referentes aos indicadores sobre o uso de materiais, água, energia e resíduos e emissões. Ressalta-se que, de acordo com a teoria da sinalização, as empresas estudadas transmitem ao mercado, por meio dos indicadores ambientais evidenciados nos relatórios, informações positivas que as discriminam junto aos stakeholders. Conclui-se que as empresas brasileiras, apesar de situadas em um país emergente, quando comparadas em termos de indicadores ambientais evidenciados, apresentam performance similar à das empresas localizadas na Espanha.

Palavras-chave: Global Reporting Initiative; Indicadores ambientais; Relatório de sustentabilidade; Stakeholders; Teoria da sinalização.

\section{ENVIRONMENTAL INDICATORS: A COMPARATIVE STUDY BETWEEN BRAZILIAN AND SPANISH COMPANIES}

\section{ABSTRACT}

The objective of this study is to verify environmental indicators used by Brazilian companies in comparison to Spanish companies based on reports, according to the Global Reporting Initiative (GRI) model, published by each companies' website since 2010. For this, sustainability reports by 280 companies from both Brazil and Spain were assessed. This is a descriptive research study of quantitative nature in which documental and bibliographical procedures were adopted. The results show that Brazilian and Spanish companies, in the total amount of evidenced indicators, present similar behavior, and the most evidenced items in the investigated companies refer to the use of materials, water, energy, and emission of residues. It is emphasized that, according to signaling theory, the studied companies transmit, through of environmental indicators disclosed in the reports, positive information that discriminate them to the stakeholders. It has been concluded that Brazilian companies, despite being located in an emerging country, when compared in terms of evidenced environmental indicators, perform similar to those of companies located in Spain.

Key words: Environmental indicators. Global reporting initiative.Signalingtheory. Stakeholders. Sustainability report. 


\section{INTRODUÇÃO}

Nos últimos anos, vem crescendo em todo o mundo a importância do papel econômico das empresas, com a consequente alavancagem de suas receitas e outros indicadores econômicofinanceiros, em decorrência da globalização dos mercados, do boom econômico global e de fusões e parcerias. Algumas empresas já apresentam receitas superiores ao Produto Interno Bruto (PIB) de muitos países. No Brasil, a situação não é diferente, quando se comparam as receitas de algumas empresas com o PIB de um estado ou município. Torna-se evidente o poder econômico das empresas e de suas decisões; mas, além de impactos econômicos, essas organizações também geram impactos sociais, políticos e ambientais, que não podem ser menosprezados (Oliveira, 2008).

Esses impactos estão relacionados ao conceito de Responsabilidade Social Empresarial (RSE), que, quando inserido nas questões estratégicas da organização, pode contribuir, de várias formas, para o crescimento de sua competitividade. Considerando-se o foco deste estudo, a RSE pode, por exemplo, ajudar a diminuir custos, quando procura reduzir o desperdício com energia e água, economizando recursos ambientais e mitigando riscos financeiros decorrentes de multas, paralisações e indenizações. Oliveira (2008) argumenta que nos últimos anos vem se desenvolvendo um grande número de normas e certificações na área socioambiental. Boa parte dessas certificações é voluntária, e as empresas optam por adquiri-las quando as acham importantes para os negócios, ou por pressão dos clientes, dos fornecedores, exigência da matriz ou ainda imitando a concorrência.

Após analisar alguns indicadores socioambientais, Willis (2003) dá ênfase aos da Global Reporting Initiative (GRI), que têm o potencial de melhorar significativamente a qualidade das informações comunicadas por empresas sobre suas atividades ambientais, sociais, seus impactos econômicos e desempenho. Segundo o estudioso, o relatório da GRI apresenta um quadro de comunicação voluntária de práticas de sustentabilidade, com o rigor equivalente ao nível dos relatórios financeiros e também sujeito a auditoria.

Willis (2003) explica que as orientações da GRI não são em si mesmas um código de conduta ou um conjunto de padrões de desempenho, nem pretendem servir como critério de seleção de decisões em investimentos. Entretanto, suas diretrizes evoluem e melhoram ao longo do tempo, de modo que os resultados dos relatórios das empresas repercutem positivamente em suas políticas, práticas e desempenho, constituindo instrumentos auxiliares dos gestores responsáveis pelos investimentos sociais e ambientais de suas carteiras.

Entre os resultados apresentados aos stakeholders, por meio do relatório GRI, destacam-se os indicadores de natureza ambiental, que refletem os esforços das empresas em relação à questão ambiental hoje amplamente debatida. Nesse contexto, a pergunta de pesquisa orientadora deste estudo é: Quais indicadores ambientais são utilizados pelas empresas brasileiras e espanholas, considerando o relatório da Global Reporting Initiative (GRI)? Com vistas a se obter uma resposta para essa questão, e levando-se em conta que o Brasil é um país emergente comparativamente à Espanha, considerada uma nação de primeiro mundo (Lores, 2002), esta pesquisa tem por objetivo verificar os indicadores ambientais utilizados pelas empresas no Brasil em comparação com as empresas localizadas na Espanha, segundo o modelo do relatório GRI.

A fundamentação teórica deste estudo se dá por meio da teoria da sinalização, segundo a qual os sinais - neste estudo representados pelos indicadores ambientais evidenciados no relatório de sustentabilidade GRI das empresas - funcionam como mecanismos de discriminação, num contexto de informação assimétrica, sendo capazes de alterar as crenças e transmitir informações a outros indivíduos (Spence, 1973).

A escolha do relatório GRI para essa comparação deve-se ao fato de se tratar da ferramenta mais aplicada nos relatórios de sustentabilidade (Instituto Ethos, 2011a) das empresas em todo o mundo. Justifica-se ainda a comparação das empresas espanholas com as empresas brasileiras por se registrar naquele país o maior número de empresas que adotam o relatório de sustentabilidade modelo GRI (Global Reporting Initiative, 2009). É importante salientar ainda que as pressões regulatórias verificadas na Europa (2000) são maiores que no Brasil. Segundo o relatório da

Revista de Gestão Social e Ambiental - RGSA, São Paulo, v. 7, n. 1, p. 35-52, jan./abr. 2013. 
Organisation for Economic Co-operation and Development (2007), no Brasil há mais facilidade de permissões e licenças do que na Espanha e não há um rigoroso controle de qualidade das regulamentações. Na Espanha, por exemplo, há regiões com legislações específicas que obrigam suas administrações públicas a publicar os resultados ambientais referentes às suas responsabilidades de controle no âmbito de proteção ambiental. Uma dessas regulamentações é a Ley 4/2009 de Protección Ambiental Integrada, da Região de Murcia, que, em seu artigo 14, dispõe sobre a corresponsabilidade das empresas que detenham licenças e autorizações ambientais para suas emissões, haja vista a necessidade de informar seus dados para alimentar o Registro Ambiental de Atividades da Região de Murcia, para posterior divulgação.

Com base no exposto, a hipótese da pesquisa é que as empresas brasileiras e as espanholas possuem características diferentes de evidenciação do total de indicadores ambientais apresentados nos seus relatórios de sustentabilidade modelo GRI.

Para se alcançar o objetivo proposto, foi realizada uma pesquisa descritiva, de natureza quantitativa, utilizando os relatórios de sustentabilidade modelo GRI de 280 empresas do Brasil e da Espanha, relativos a 2009, divulgados nos websites das empresas a partir de 2010.

Este estudo foi dividido em seis tópicos, incluindo esta introdução. O segundo, compõe o arcabouço teórico que serve como fundamentação para a pesquisa. $\mathrm{O}$ terceiro, aborda a metodologia da pesquisa, apresentando a forma como os dados foram obtidos e as análises estatísticas utilizadas. No tópico 4, são debatidos os resultados encontrados, e, no quinto e último tópico são apresentadas as conclusões da pesquisa.

\section{MARCO TEÓRICO}

Neste capítulo são apresentados alguns aspectos sobre a Teoria da Sinalização, Relatórios de Sustentabilidade e Indicadores Ambientais. Também, efetua-se abordagem sobre as Diretrizes Ambientais Brasileiras e Espanholas.

\subsection{Teoria da sinalização, relatório de sustentabilidade e indicadores ambientais}

As ações humanas vêm afetando e transformando substancialmente a natureza, e, nesse cenário, as empresas são consideradas os agentes mais poluidores. O conceito de desenvolvimento sustentável teve sua origem em movimentos ambientalistas de meados do século XIX, denunciando efeitos negativos sobre o meio ambiente gerados pela crescente industrialização e pela ocupação de áreas para exploração agrícola e mineral em suas mais diversas formas de organização (Barbieri \& Cajazeira, 2009; Oliveira, 2008).

Barbieri (2007) explica que as preocupações ambientais dos empresários são influenciadas por três grandes grupos que se interagem: o governo, a sociedade e o mercado. Esse autor adverte que se não houvesse pressões da sociedade e medidas governamentais, não haveria tanto engajamento das empresas na questão ambiental.

A proatividade ambiental das empresas, portanto, está ligada à pressão dos stakeholders e a questões como a aplicação voluntária das práticas ambientais e suas iniciativas destinadas a melhorar o desempenho ambiental, o que é corroborado por Gonzalez-Benito e Gonzalez-Benito (2006), ao afirmarem que o compromisso com o meio ambiente tornou-se uma variável importante nos atuais cenários competitivos, e isso tem estimulado muitas empresas a fazer transformações voluntárias para seguir princípios ecologicamente corretos. Tais transformações têm dado origem a diversas estratégias ambientais, que variam entre duas posições extremas: a reatividade ambiental (típica de empresas que apenas implementam as mudanças mínimas obrigatórias) e a proatividade ambiental (própria daquelas que adotam medidas voluntárias para reduzir seu impacto sobre o meio ambiente).

Segundo Gonzalez-Benito e Gonzalez-Benito (2006), a proatividade ambiental pode se manifestar por meio de diferentes práticas e estratégias, sendo inúmeras as variáveis que parecem influenciar a decisão de implementar tais estratégias. A pressão dos stakeholders é considerada fator

Revista de Gestão Social e Ambiental - RGSA, São Paulo, v. 7, n. 1, p. 35-52, jan./abr. 2013. 
central e determinante para as empresas, e argumenta-se que todas as demais variáveis afetam tanto a intensidade dessa pressão quanto a capacidade da empresa de percebê-la. Os relatórios de sustentabilidade das empresas emergem como forma de responder a essas pressões.

Lins e Silva (2009) destacam que se tornou fator relevante para as decisões estratégicas das empresas a forma como elas são percebidas pela sociedade. O receio de comprometer a imagem institucional perante a sociedade tem levado as empresas a buscar um diferencial em relação a sua postura no quesito responsabilidade social e ambiental, e é fato que toda postura socioambiental efetiva pode e deve ser divulgada pelas empresas que a praticam de forma sistemática. Os autores explicam ainda que o disclosure ambiental constitui importante meio de comunicação (transparência) sobre o desempenho da empresa aos seus stakeholders, reduzindo a assimetria de informações entre os gestores, os interessados e, especialmente, os investidores.

No âmbito econômico, Anand e Shachar (2007) e Kalra e Li (2008) reiteram que quaisquer métodos de envio de informações relevantes ao mercado - como o relatório de sustentabilidade podem ser enquadrados como sinais. De acordo com Dewally e Ederington (2006), os sinais econômicos correspondem àquelas atividades realizadas pelos agentes para informar o mercado sobre características relevantes para sua diferenciação perante a concorrência (ou que os mantenha ao menos em um nível comparável de competitividade).

Nossa et al. (2009, p. 123) argumentam que "[...] a decisão de investir em um ou outro projeto social/ambiental fica a critério do gestor, assim o acionista não tem acesso à informação de que o projeto social/ambiental pode ser uma sinalização positiva ou não para a empresa diante do mercado acionário". Dessa forma, Spence (1973) adverte que, segundo a teoria da sinalização, na medida em que as empresas assumem sinais, elas podem sinalizar de forma neutra, positiva ou negativa junto às partes interessadas. Esse cenário pode levar um sinal positivo para o mercado acionário, de acordo com as estratégias assumidas pelos gestores.

A teoria pode ser utilizada pelas empresas para sinalizar a atração de novos investidores e captar recursos. Por meio de seus mecanismos e práticas, elas podem oferecer retornos, destacar boas oportunidades de investimento, além de comunicar e assegurar aos interessados, sua qualidade, credibilidade informacional e minimizar as falhas de agência.

Do exposto, e em consonância com Akerlof (1970) e Spence (1973), esta pesquisa considera a sinalização um elemento de redução de assimetria informacional e, consequentemente, de diferenciação em mercados com fluxos imperfeitos de informação. Assim, os relatórios ambientais podem ser entendidos como sinais, representados por comunicações veiculadas por meio impresso ou eletrônico, para divulgar informações sobre aspectos ambientais das organizações, os impactos gerados e as medidas implementadas, que possam discriminar as empresas para os stakeholders.

Os relatórios ambientais podem ter origem legal ou voluntária. As empresas podem elaborar seus relatórios de forma independente, ou optar por seguir diretrizes específicas de modelos de relatórios existentes.

Vieira (2009) argumenta que o público e os tomadores de decisão estão interessados em obter informações confiáveis e sucintas sobre o meio ambiente sem prolongamentos desnecessários. Os indicadores ambientais apresentados nos relatórios oferecem essas informações à medida que permitem conhecer o estado do meio ambiente e como ele vem se modificando de forma direta e objetiva, além de descreverem como uma nação ou empresa vem progredindo em relação às metas de desenvolvimento sustentável.

Maia, Martos e Barrela (2001) ressaltam que a intensidade com que o meio ambiente é explorado põe em risco a estabilidade dos ecossistemas e a própria existência do homem e de outras espécies. Nesse sentido, destacam a importância da quantificação e qualificação das condições ambientais que vêm sendo modificadas, preservadas ou estudadas, daí a necessidade de avaliações precisas, por meio de indicadores.

Vieira (2009) mostra que o interesse pela utilização dos indicadores para avaliação ambiental cresce diante da preocupação em conhecer e comprovar se as ações de planejamento, 
controle e os programas implantados são efetivos e alcançam o objetivo geral da preservação ambiental, garantindo o bem-estar, a saúde e a vida da população.

Segundo Vieira (2009), instituições internacionais, tais como a Organização das Nações Unidas (ONU), a Agência de Proteção Ambiental dos Estados Unidos da América (EPA) e a Agência Europeia do Ambiente (AEA), são pioneiras na elaboração de indicadores, desenvolvendo um conjunto de estudos que estimula a sistematização e a comparabilidade das informações nos diversos países participantes.

Destaca-se que os indicadores podem ser tão variados quanto os sistemas de gestão ambiental que se pretendem avaliar e medir. Entretanto, para serem efetivos, devem atender a determinadas características: precisam ser quantificáveis, pertinentes, compreensíveis, confiáveis e acessíveis (Vieira, 2009). Entre os modelos mais conhecidos, destacam-se o do Instituto Brasileiro de Análises Sociais e Econômicas (IBASE) e o da GRI (Barbieri, 2007).

Segundo a GRI (2006), "Relatório de Sustentabilidade" é um termo amplo que pode ser considerado sinônimo de outros relatórios que se propõem descrever os impactos econômicos, ambientais e sociais (Triple Bottom Line) de uma organização, como o relatório de RSE e o balanço social. Elaborar relatórios de sustentabilidade significa medir, divulgar e prestar contas para stakeholders internos e externos acerca do desempenho organizacional, visando ao desenvolvimento sustentável (GRI, 2006).

A Global Reporting Initiative (GRI, 2006) é uma organização pioneira em questões relacionadas à sustentabilidade, comprometida com a melhoria contínua do quadro de indicadores que compõem o modelo do seu relatório, que hoje tem aplicação em todo o mundo. Entre os objetivos fundamentais da GRI, destaca-se a integração da divulgação do desempenho ambiental, social e de governança.

Segundo as diretrizes da GRI (2006), os relatórios de sustentabilidade podem ser empregados para demonstrar o compromisso da organização com o desenvolvimento sustentável, para comparar o desempenho organizacional ao longo do tempo, e para medir esse mesmo desempenho com respeito às leis, normas, aos padrões e às iniciativas voluntárias.

A GRI promove uma abordagem padronizada de comunicação e estimula a demanda por informações sobre sustentabilidade, beneficiando as organizações e os usuários de relatórios dessa natureza. Segundo Oliveira (2008), a GRI tem por objetivo desenvolver diretrizes para publicação de informações de sustentabilidade das empresas (informações econômicas, ambientais e sociais).

O Instituto Ethos afirma que a GRI é atualmente o "[...] modelo mais completo e mundialmente difundido" (Instituto Ethos, 2011b). A GRI adota uma abordagem multistakeholders, pois compreende em suas diretrizes o engajamento com os stakeholders como um dos elos principais. A GRI representa uma estrutura para a elaboração de relatórios de sustentabilidade, podendo ser utilizado por organizações de todos os tamanhos, setores e localidades (GRI, 2006).

Para atender às necessidades das organizações, os relatos podem ser classificados nos níveis iniciante (C), intermediário (B) e avançado (C). Os critérios de relato encontrados em cada um dos níveis indicam a evolução da aplicação ou cobertura da estrutura de relatórios da GRI pela organização. Uma organização pode autodeclarar-se com um ponto a mais $(+)$ em cada nível (por exemplo, $\mathrm{C}+, \mathrm{B}+, \mathrm{A}+$ ), caso tenha submetido seu relatório a uma verificação externa (GRI, 2006). A figura 1 apresenta o modelo GRI com seus respectivos níveis. 


\begin{tabular}{|c|c|c|c|c|c|c|}
\hline $\begin{array}{l}\text { Relatório dos } \\
\text { níveis de } \\
\text { aplicação }\end{array}$ & $\mathbf{C}$ & \begin{tabular}{l|}
$\mathbf{C}$ \\
+ \\
$\mathrm{C}$
\end{tabular} & $\mathbf{B}$ & $\begin{array}{l}\mathbf{B} \\
+ \\
\mathrm{C}\end{array}$ & $\mathbf{A}$ & $\begin{array}{l}\mathbf{A} \\
+ \\
\mathrm{C}\end{array}$ \\
\hline Perfil da G3 & $\begin{array}{l}\text { Responder aos itens: } \\
1.1 ; \\
2.1 \text { a } 2.10 ; \\
3.1 \text { a } 3.8 ; 3.10 \text { a } 3.12 ; \\
4.1 \text { a } 4.4,4.14 \text { e } 4.15 \text {. }\end{array}$ & $\begin{array}{l}\mathrm{o} \\
\mathrm{m} \\
\mathrm{V} \\
\mathrm{e} \\
\mathrm{r} \\
\mathrm{i}\end{array}$ & $\begin{array}{l}\text { Responder a todos os } \\
\text { critérios elencados para o } \\
\text { nível C+: } \\
1.2 ; \\
3.9,3.13 ; \\
4.5 \text { a } 4.13 ; 4.16 \text { e } 4.17\end{array}$ & $\begin{array}{l}\mathrm{o} \\
\mathrm{m} \\
\mathrm{V} \\
\mathrm{e} \\
\mathrm{r}\end{array}$ & $\begin{array}{l}\text { O mesmo exigido } \\
\text { para o nível B }\end{array}$ & $\begin{array}{l}\mathrm{o} \\
\mathrm{m} \\
\mathrm{V} \\
\mathrm{e} \\
\mathrm{r} \\
\mathrm{i}\end{array}$ \\
\hline $\begin{array}{l}\text { Informações } \\
\text { sobre a Forma } \\
\text { de Gestão da G3 }\end{array}$ & Não exigido & $\begin{array}{l}\text { f } \\
\text { i } \\
\text { c } \\
\text { a }\end{array}$ & $\begin{array}{l}\text { Informações sobre a } \\
\text { forma de gestão para } \\
\text { cada categoria de } \\
\text { indicador }\end{array}$ & $\begin{array}{l}\mathrm{f} \\
\mathrm{i} \\
\mathrm{c} \\
\mathrm{a}\end{array}$ & $\begin{array}{l}\text { Forma de gestão } \\
\text { divulgada para cada } \\
\text { categoria de indicador }\end{array}$ & $\begin{array}{l}\mathrm{f} \\
\mathrm{i} \\
\mathrm{c} \\
\mathrm{a}\end{array}$ \\
\hline $\begin{array}{l}\text { Indicadores de } \\
\text { Desempenho da } \\
\text { G3 e Indicadores } \\
\text { de Desempenho } \\
\text { do Suplemento } \\
\text { Setorial }\end{array}$ & $\begin{array}{l}\text { Responder a um } \\
\text { mínimo de } 10 \\
\text { indicadores de } \\
\text { desempenho, } \\
\text { incluindo, pelo } \\
\text { menos, um de cada } \\
\text { uma das seguintes } \\
\text { áreas de desempenho: } \\
\text { social, econômico e } \\
\text { ambiental. }\end{array}$ & $\begin{array}{l}\mathrm{c} \\
\tilde{a} \\
\mathrm{o} \\
\mathrm{E} \\
\mathrm{x} \\
\mathrm{t} \\
\mathrm{e} \\
\mathrm{r} \\
\mathrm{n} \\
\mathrm{a}\end{array}$ & $\begin{array}{l}\text { Responder a um mínimo } \\
\text { de } 20 \text { indicadores de } \\
\text { desempenho, incluindo, } \\
\text { pelo menos, um de cada } \\
\text { uma das seguintes áreas } \\
\text { de desempenho: social, } \\
\text { econômico, ambiental, } \\
\text { direitos humanos, } \\
\text { práticas trabalhistas, } \\
\text { sociedade, } \\
\text { responsabilidade pelo } \\
\text { produto }\end{array}$ & $\begin{array}{l}\mathrm{E} \\
\mathrm{x} \\
\mathrm{t} \\
\mathrm{e} \\
\mathrm{r} \\
\mathrm{n} \\
\mathrm{a}\end{array}$ & $\begin{array}{l}\text { Responder a cada } \\
\text { indicador essencial da } \\
\text { G3 e do suplemento } \\
\text { setorial* com a devida } \\
\text { consideração ao } \\
\text { princípio da } \\
\text { materialidade de uma } \\
\text { das seguintes formas: } \\
\text { a) respondendo ao } \\
\text { indicador ou b) } \\
\text { explicando o motivo } \\
\text { da emissão }\end{array}$ & $\begin{array}{l}E \\
x \\
t \\
e \\
r \\
n \\
a\end{array}$ \\
\hline
\end{tabular}

Figura 1- Níveis de evidenciação, segundo o GRI

Fonte: Adaptado de GRI (2006).

Conforme pode ser observado na figura 1, o relatório deve conter informações acerca do perfil, da forma de gestão e dos indicadores de desempenho. Com relação aos indicadores de desempenho, a GRI os classifica em sociais, econômicos e ambientais. Neste estudo, são utilizados os 30 indicadores ambientais compreendidos no modelo G3 GRI.

Os indicadores do GRI são ainda classificados em Essenciais, identificados nas diretrizes da GRI como de interesse da maioria dos stakeholders e considerados relevantes; e Adicionais, identificados nas diretrizes da GRI como práticas emergentes ou que tratam de temas que podem ser relevantes para algumas organizações, mas que nem sempre o são para a maioria (GRI, 2006).

\subsection{Diretrizes Ambientais Brasileiras}

A Lei ${ }^{\circ} 10.165$, de 27 de dezembro de 2000, dispõe sobre a Política Nacional do Meio Ambiente. Além de dispositivos legais que devem ser observados por todas as organizações, alguns órgãos reguladores estabelecem diretrizes que devem ser seguidas por setores específicos.

Com o objetivo de contribuir para a prática de evidenciação de informações socioambientais das empresas, o Conselho Federal de Contabilidade editou a Resolução $n^{\circ}$ 1.003/2004 (2004), aprovando a Norma Brasileira de Contabilidade NBC T 15, que estabelece os procedimentos para evidenciação de informações de natureza social e ambiental. Além das informações sobre riqueza, recursos humanos e interação com a comunidade, a NBC T 15 dispõe sobre a evidenciação das seguintes informações sobre o meio ambiente: todos os investimentos e gastos com melhoria, preservação e recuperação do meio ambiente, com educação ambiental de empregados, administradores e comunidade, além de passivos e contingências ambientais. Ainda de acordo com a NBC T 15, a Demonstração de Informações de Natureza Social e Ambiental deverá ser auditada e incluída no relatório da auditoria, quando a empresa for passível de tal procedimento, para garantir a confiabilidade dos dados, como é feito com as demonstrações contábeis já divulgadas pelas empresas. 
Segundo Lins e Silva (2009), desde 2005, a Bolsa de Valores, Mercadorias e Futuros BM\&F/Bovespa adota o Índice de Sustentabilidade Empresarial (ISE), aplicado ao mercado de ações que utiliza o conceito Triple Botton Line, ou seja, avalia, de forma integrada, as dimensões econômico-financeiras, sociais e ambientais das empresas. O ISE foi criado com a finalidade de atender a uma demanda crescente de investidores preocupados em aplicar seus recursos em investimentos socialmente responsáveis. O ISE foi desenvolvido para servir como um instrumento de benchmark e também indutor de boas práticas de sustentabilidade no meio empresarial brasileiro (BMF \& Bovespa, 2011).

Gasparino (2006) afirma que, por meio do Parecer de Orientação n 15/1987, a Comissão de Valores Mobiliários (CVM) recomenda que as empresas brasileiras divulguem em seu relatório administrativo anual, juntamente com as demonstrações contábeis, informações sobre seus investimentos em benefício ambiental, além da sua conduta com as questões ambientais.

O Brasil conta também com o Instituto Ethos de Empresas e Responsabilidade Social, ONG criada em 2000. Os Indicadores Ethos auxiliam as empresas a incorporar em sua gestão conceitos e compromissos em favor da responsabilidade social e do desenvolvimento sustentável. Os referidos indicadores encontram em processo de revisão, prevendo-se para outubro de 2012 o lançamento da versão final, que deverá apresentar convergência com os indicadores da GRI e da ISO 26000 Norma Internacional de Responsabilidade Social (Instituto Ethos, 2011a).

Embora ainda seja inexpressivo o número de empresas que divulgam resultados ambientais, destacam-se as instituições que apoiam e direcionam mudanças comportamentais empresariais nessa área. As empresas que já se sensibilizaram com a temática têm nessa iniciativa um diferencial competitivo (Gasparino, 2006).

\subsection{Diretrizes ambientais da Comunidade Europeia e da Espanha}

A Comissão das Comunidades Europeias (2001) organizou o Livro Verde, que tem por finalidade promover um quadro europeu para a responsabilidade social das empresas. O Livro Verde mostra um número crescente de empresas europeias que procura promover estratégias de responsabilidade social, em reação a diversas pressões de natureza social, ambiental e econômica.

Segundo o disposto no Livro Verde, ao assumirem de maneira voluntária compromissos que vão além dos requisitos reguladores e afirmarem sua responsabilidade social, as empresas buscam elevar o grau de exigência com o desenvolvimento social, a proteção ambiental e o respeito aos direitos fundamentais, com o intuito de conciliar os interesses dos stakeholders, numa abordagem global de qualidade e de desenvolvimento sustentável, e esperam que esse compromisso voluntário contribua para o aumento da sua rentabilidade.

A Comunidade Europeia reúne muitas ações ambientais em sua pauta, com destaque para a melhoria do uso dos recursos ambientais na política energética. A Espanha é um país atuante na gestão ambiental, sendo participante ativo do Pacto de Autarcas - compromisso assumido pelas cidades e municípios signatários que têm por objetivo ultrapassar as metas traçadas pela política energética na União Europeia - em matéria de redução das emissões de $\mathrm{CO}_{2}$ por meio do aumento da eficiência energética e de uma produção e utilização mais limpa. Entre os 13 países que assinaram o tratado, a Espanha conta com maior número de cidades signatárias (583), seguida pela Itália (443) e pela França (104). Os demais países possuem, individualmente, até quatro dezenas de cidades representadas (Comissão Europeia, 2010).

O grande número de cidades espanholas signatárias do Pacto de Autarcas, comprometidas com os resultados ambientais, evidencia o comprometimento do país hispânico com o tema e expressa toda sua cultura ambiental latente. Isso pode explicar o fato de que em certas regiões da Espanha há leis que obrigam suas respectivas administrações públicas a publicar resultados ambientais referentes às suas responsabilidades de controle no âmbito da proteção ambiental integrada, a exemplo do artigo 14, da Lei 4/2009 (2009) de Protección Ambiental Integrada, da Região de Murcia - Espanha, que assim dispõe:

Revista de Gestão Social e Ambiental - RGSA, São Paulo, v. 7, n. 1, p. 35-52, jan./abr. 2013. 
1. A criação do Cadastro Ambiental de Atividades na Região de Murcia deverá conter os dados relacionados às atividades, seus proprietários, as condições para seu exercício e as principais emissões, de acordo com os resultados de autorizações e licenças concedidas, as informações disponíveis ou as fornecidas pelos proprietários.

2. Os municípios devem disponibilizar informações sistematizadas, que devem conter os detalhes das atividades, seus proprietários e concessão de licenças de exploração para fins de sua apresentação ao órgão competente da Região Autônoma para inclusão no Registo citado.

O artigo 14 da Lei 4/2009 (2009) dispõe ainda que esses regulamentos devem orientar o conteúdo do registro e do processo de comunicação de dados entre as diferentes administrações públicas da Região de Murcia e que o registro ambiental dessas atividades será acessível ao público, segundo as normas vigentes do direito de acesso sobre informação de matérias acerca do meio ambiente.

Corroborando a importância dessas informações no ambiente espanhol, Antonio (2009) afirma que desde 1978, a Constituição da Espanha traz, em seu artigo 45, a menção ao direito de todos ao desfrute do meio ambiente adequado e seu dever de conservação e prescreve o zelo dos poderes públicos com a utilização racional dos recursos naturais com o objetivo de proteger e melhorar a qualidade de vida. $\mathrm{O}$ autor menciona ainda que o artigo 148 da Constituição trata das competências que podem ser assumidas pelas Comunidades Autônomas sobre gestão ambiental e aproveitamento florestal, enquanto o artigo 149 traça as competências legislativas entre o Estado e as Comunidades Autônomas.

\section{METODOLOGIA}

Considerando-se o seu objetivo, essa pesquisa se caracteriza como descritiva e tem natureza quantitativa, pois se propõe apresentar as características dos indicadores ambientais evidenciados pelas empresas brasileiras e espanholas que utilizam o modelo GRI. A abordagem quantitativa ali adotada visa validar a hipótese do estudo e, por meio de análise estatística, garantir a precisão dos resultados, evitando distorção de análise e interpretação (Richardson, 2008).

Conforme já mencionado, a escolha de empresas da Espanha para comparação com empresas do Brasil deve-se ao fato de aquele país europeu ser o que apresenta mais relatórios de sustentabilidade com base no modelo GRI em todo o mundo (GRI, 2009). Isso gera o interesse de se verificar se as empresas espanholas apresentam características diferentes em comparação com as brasileiras no tocante à evidenciação ambiental. Dessa forma, a hipótese da pesquisa é a seguinte: as empresas brasileiras e as espanholas possuem características diferentes de evidenciação do total de indicadores ambientais em seus relatórios de sustentabilidade modelo GRI.

Nesse sentido, foram analisados os relatórios de sustentabilidade de 280 empresas dos dois países que adotaram o modelo da Global Reporting Initiative em seus relatórios divulgados a partir de 2010, referente ao ano de 2009. De acordo com a GRI (2011), 303 empresas dos dois países adotam o modelo GRI, sendo 134 brasileiras e 169 espanholas. O acesso aos relatórios de sustentabilidade se deu por meio dos websites das empresas constantes da lista da GRI (2011). Como alguns relatórios de sustentabilidade não estavam disponíveis nos respectivos endereços eletrônicos, a amostra ficou reduzida a 280 empresas, sendo 124 brasileiras e 156 espanholas.

Em cada relatório de sustentabilidade foram analisados todos os indicadores ambientais ali consignados. Esses indicadores foram distribuídos, segundo a classificação do relatório GRI, em dois grupos: Essenciais e Adicionais. Foi atribuído o valor "1" para cada indicador apresentado pela empresa no relatório e "0" para cada ausência de indicador, contabilizando-se o número de respostas de cada grupo de indicadores ambientais GRI.

Os indicadores ambientais do relatório GRI correspondem a 30 indicadores distribuídos nas categorias Materiais, Energia, Água, Biodiversidade, Emissões, efluentes e resíduos, Produtos e serviços, Conformidade legal, Transporte e Geral, como mostra a figura 2.

Revista de Gestão Social e Ambiental - RGSA, São Paulo, v. 7, n. 1, p. 35-52, jan./abr. 2013. 


\begin{tabular}{|c|c|c|}
\hline Categoria & \begin{tabular}{|l|} 
Grupo \\
E=Essenciais \\
A=Adicionais \\
\end{tabular} & Indicadores \\
\hline \multirow{2}{*}{ Materiais } & $\mathbf{E}$ & EN1 - Materiais usados, por peso ou volume \\
\hline & $\mathbf{E}$ & EN2 - Percentual dos materiais usados provenientes de reciclagem \\
\hline \multirow{5}{*}{ Energia } & $\mathbf{E}$ & EN3 - Consumo de energia direta, discriminado por fonte de energia primária \\
\hline & $\mathbf{E}$ & EN4 - Consumo de energia indireta, discriminado por fonte primária \\
\hline & $\mathbf{A}$ & EN5 - Energia economizada em decorrência de melhorias em conservação e eficiência \\
\hline & A & $\begin{array}{l}\text { EN6 - Iniciativas para fornecer produtos e serviços com baixo consumo de energia, ou } \\
\text { que usem energia gerada por recursos renováveis, e a redução da necessidade de } \\
\text { energia daí resultante }\end{array}$ \\
\hline & $\mathbf{A}$ & EN7 - Iniciativas para reduzir o consumo de energia indireta, e a redução obtida \\
\hline \multirow{3}{*}{ Água } & $\mathbf{E}$ & EN8 - Total de retiradas de água, por fonte \\
\hline & $\mathbf{A}$ & EN9 - Fontes hídricas significativamente afetadas por retiradas de água \\
\hline & $\mathbf{A}$ & EN10 - Percentual e volume total de água reciclada e reutilizada \\
\hline \multirow{5}{*}{$\begin{array}{l}\text { Biodiver- } \\
\text { sidade }\end{array}$} & $\mathbf{E}$ & $\begin{array}{l}\text { EN11 - Localização e tamanho da área possuída, arrendada ou administrada dentro de } \\
\text { áreas protegidas, ou adjacentes a elas, e áreas de alto índice de biodiversidade fora das } \\
\text { áreas protegidas }\end{array}$ \\
\hline & $\mathbf{E}$ & $\begin{array}{l}\text { EN12 - Descrição de impactos significativos na biodiversidade de atividades, } \\
\text { produtos e serviços em áreas protegidas e em áreas de alto índice de biodiversidade } \\
\text { fora das áreas protegidas }\end{array}$ \\
\hline & $\mathbf{A}$ & EN13 - Habitats protegidos ou restaurados \\
\hline & A & $\begin{array}{l}\text { EN14 - Estratégias, medidas em vigor e planos para a gestão de impactos na } \\
\text { biodiversidade }\end{array}$ \\
\hline & A & $\begin{array}{l}\text { EN15 - Número de espécies na Lista Vermelha da IUCN e em listas nacionais de } \\
\text { conservação com habitats em áreas afetadas por operações, discriminadas pelos } \\
\text { respectivos níveis de risco de extinção }\end{array}$ \\
\hline \multirow{10}{*}{$\begin{array}{l}\text { Emissões, } \\
\text { efluentes e } \\
\text { resíduos }\end{array}$} & $\mathbf{E}$ & EN16 - Total de emissões diretas e indiretas de gases de efeito estufa, por peso \\
\hline & $\mathbf{E}$ & EN17 - Outras emissões indiretas relevantes de gases de efeito estufa, por peso \\
\hline & A & $\begin{array}{l}\text { EN18 - Iniciativas para reduzir as emissões de gases de efeito estufa, e as reduções } \\
\text { obtidas }\end{array}$ \\
\hline & $\mathbf{E}$ & EN19 - Emissões de substâncias destruidoras da camada de ozônio, por peso \\
\hline & $\mathbf{E}$ & EN20 - NOx, SOx e outras emissões atmosféricas significativas, por tipo e peso \\
\hline & $\mathbf{E}$ & EN21 - Descarte total de água, por qualidade e destinação \\
\hline & $\mathbf{E}$ & EN22 - Peso total de resíduos, por tipo e método de disposição \\
\hline & $\mathbf{E}$ & EN23 - Número e volume total de derramamentos significativos \\
\hline & A & $\begin{array}{l}\text { EN24 - Peso de resíduos transportados, importados, exportados ou tratados } \\
\text { considerados perigosos nos termos da Convenção da Basileia } 13 \text { e percentual de } \\
\text { carregamento de resíduos transportados internacionalmente }\end{array}$ \\
\hline & A & $\begin{array}{l}\text { EN25 - Identificação, tamanho, status de proteção e índice de biodiversidade de } \\
\text { corpos d'água e habitats significativamente afetados por descartes de água e drenagem } \\
\text { realizados pela organização relatora }\end{array}$ \\
\hline \multirow{2}{*}{$\begin{array}{l}\text { Produtos e } \\
\text { serviços }\end{array}$} & $\mathbf{E}$ & $\begin{array}{l}\text { EN26 - Iniciativas para mitigar os impactos ambientais de produtos e serviços, e sua } \\
\text { extensão de redução }\end{array}$ \\
\hline & $\mathbf{E}$ & $\begin{array}{l}\text { EN27 - Percentual de produtos e suas embalagens recuperadas, em relação ao total de } \\
\text { produtos vendidos }\end{array}$ \\
\hline $\begin{array}{l}\text { Confor- } \\
\text { midade } \\
\text { legal }\end{array}$ & $\mathbf{E}$ & $\begin{array}{l}\text { EN28 - Valor monetário de multas significativas e número total de sanções não- } \\
\text { monetárias resultantes da não-conformidade com leis e regulamentos ambientais }\end{array}$ \\
\hline $\begin{array}{l}\text { Trans- } \\
\text { porte }\end{array}$ & A & $\begin{array}{l}\text { EN29 - Impactos ambientais significativos do transporte de produtos e outros bens e } \\
\text { materiais utilizados nas operações da organização, bem como do transporte de } \\
\text { trabalhadores }\end{array}$ \\
\hline Geral & $\mathbf{A}$ & EN30 - Total de investimentos e gastos em proteção ambiental, por tipo \\
\hline
\end{tabular}

Figura 2 - Indicadores ambientais - modelo GRI

Fonte: GRI (2006).

Para fins de análise, os indicadores ambientais utilizados pelas empresas brasileiras e espanholas foram tratados individualmente e, posteriormente, nos grupos de indicadores, conforme apresentado na figura 2 .

Revista de Gestão Social e Ambiental - RGSA, São Paulo, v. 7, n. 1, p. 35-52, jan./abr. 2013. 
A estatística descritiva possibilitou a análise geral dos dados. Foi realizada também uma análise de dados cruzados, levando em conta o país e o nível de evidenciação, segundo a classificação do GRI (A, B e C). Foram calculadas também as médias dos grupos dos indicadores ambientais analisados (Materiais, Energia, Água, Biodiversidade, Emissões, efluentes e resíduos, Produtos e serviços, Conformidade legal, Transporte e Geral), e dos indicadores Essenciais, Adicionais e totais.

Após essa análise, aplicou-se o teste não-paramétrico de Mann-Whitney, para se avaliar se há diferença significativa entre duas condições e diferentes participantes (Dancey \& Reidy, 2006). Esse teste foi utilizado devido à não-normalidade dos dados auferida com a aplicação do teste Kolmogorov-Smirnov, que tem por objetivo determinar se uma amostra provém de uma distribuição normal (Fávero et al., 2009). Assim, a comparação das médias dos grupos de indicadores ambientais evidenciados no Brasil e na Espanha foi realizada por meio do teste de Mann-Whitney.

Este estudo adotou o nível de significância correspondente a 5\%, indicando $95 \%$ de segurança na fidedignidade dos resultados. Os dados da pesquisa foram processados com o auxílio do software estatístico Statistical Package for the Social Science - SPSS 19.

\section{APRESENTAÇÃO E ANÁLISE DOS RESULTADOS}

Inicialmente, constatou-se que os indicadores mais evidenciados pelas empresas dos dois países fazem parte dos grupos de Materiais (EN1 e EN2), Energia (EN3 e EN4), Água (EN8), Emissões, efluentes e resíduos (EN16, EN18 e EN22), Produtos e serviços (EN26) e Conformidade legal (EN28), levando-se em conta a evidenciação acima de $60 \%$ pelas empresas (Tabela 1). Destaca-se que, com exceção do EN18, os indicadores mais evidenciados pelas empresas pertencem ao grupo Essenciais do modelo GRI. A justificativa para a ocorrência de um indicador do grupo Adicionais (EN18) nesse nível de evidenciação pode ser atribuída à crescente preocupação com as mudanças climáticas por parte dos diversos stakeholders que influenciam as empresas, exigindo que elas implementem medidas para redução de suas emissões de gases causadores do efeito estufa (Lash \& Wellington, 2007).

Tabela 1- Indicadores ambientais mais evidenciados pelas empresas no Brasil e na Espanha

\begin{tabular}{l|l|l|l|l}
\hline Cód. & Indicador & $\begin{array}{l}\text { Total } \\
\boldsymbol{\%}\end{array}$ & $\begin{array}{l}\text { Brasil } \\
\boldsymbol{\%}\end{array}$ & $\begin{array}{l}\text { Espanha } \\
\text { \% }\end{array}$ \\
\hline EN1 & Materiais usados, por peso ou volume & 75,0 & 63,7 & 84,0 \\
\hline EN2 & Percentual dos materiais usados provenientes de reciclagem & 62,1 & 54,8 & 67,9 \\
\hline EN3 & Consumo de energia direta, discriminado por fonte de energia primária & 83,2 & 79,0 & 86,5 \\
\hline EN4 & Consumo de energia indireta, discriminado por fonte primária & 71,4 & 58,1 & 82,0 \\
\hline EN8 & Total de retiradas de água, por fonte & 83,6 & 81,4 & 85,3 \\
\hline EN16 & Total de emissões diretas e indiretas de gases de efeito estufa, por peso & 74,6 & 65,3 & 82,0 \\
\hline EN18 & $\begin{array}{l}\text { Iniciativas para reduzir as emissões de gases de efeito estufa, e as } \\
\text { reduções obtidas }\end{array}$ & 63,2 & 61,3 & 64,7 \\
\hline EN22 & Peso total de resíduos, por tipo e método de disposição & 78,2 & 78,2 & 78,2 \\
\hline EN26 & $\begin{array}{l}\text { Iniciativas para mitigar os impactos ambientais de produtos e serviços, } \\
\text { e sua extensão de redução }\end{array}$ & 71,8 & 68,5 & 74,4 \\
\hline EN28 & $\begin{array}{l}\text { Valor monetário de multas significativas e número total de sanções } \\
\text { não-monetárias resultantes da não-conformidade com leis e } \\
\text { regulamentos ambientais }\end{array}$ & 71,1 & 61,3 & 78,8 \\
\hline Fonte: & Dados da pesquisa & & \\
\hline
\end{tabular}

Fonte: Dados da pesquisa

Entre os indicadores evidenciados pelas empresas brasileiras, destacam-se o EN8 (81,4\%), o EN3 (79\%) e o EN22 (78,2\%), relacionados a Água, Energia e Emissões, efluentes e resíduos, respectivamente. No Brasil, torna-se mais fácil a mensuração de tais indicadores, já que há órgãos reguladores e fiscalizadores das atividades de alguns setores que, ao regular, facilitam a divulgação 
desses quesitos. Para a Água, por exemplo, há a Agência Nacional das Águas - ANA), criada pela Lei $n^{\circ}$ 9.984/2000 (2000a); para a Energia, há a Resolução n 456/2000, da Agência Nacional de Energia Elétrica - Aneel (2000b), que estabelece as condições gerais de fornecimento de energia elétrica; e, embora recente, ressalta-se a edição da Lei de Resíduos Sólidos n 12.305/2010 (2010). Destaca-se ainda a Lei ${ }^{\circ}$ 9.605/1998 (1998), que dispõe sobre sanções penais e administrativas decorrentes de condutas e atividades lesivas ao meio ambiente.

Na Espanha, destaca-se a evidenciação dos indicadores EN3 (86,5\%), EN1 (84\%), EN8 (85,3\%), EN4 (82\%) e EN16 (82\%). Percebe-se uma forte evidenciação dos indicadores do grupo Essenciais da categoria Energia (EN3 e EN4). A Espanha é o país europeu com o maior número de cidades signatárias (583) do Pacto de Autarcas, iniciativa da Comissão Europeia que recebeu o apoio do Parlamento Europeu e do Comitê das Regiões, cuja finalidade é fazer com que as cidades europeias signatárias se comprometam a poupar energia, promover energias renováveis e sensibilizar os cidadãos por meio do desenvolvimento e implementação de planos de ação em matéria de energia sustentável (União Europeia, 2010). Quanto ao indicador EN16, relativo às emissões dos gases causadores do efeito estufa (GEEs), a grande representatividade deve-se também à alta preocupação dos países da União Europeia com essa questão, dado que a Espanha, assim como os demais países da Comunidade Europeia, ratificou o Protocolo de Quioto, comprometendo-se a reduzir as emissões de GEEs em 5\%, durante o período de 2008 a 2012, em relação às emissões de 1990. Segundo o Relatório Geral sobre a atividade da União Europeia (União Europeia, 2010), o bloco é líder mundial no movimento de mitigação das mudanças climáticas.

O indicador EN1 diz respeito à quantidade de materiais usados, por peso ou volume, sendo o papel o mais considerado nos relatórios de sustentabilidade das empresas estudadas. Analisandose esse indicador, juntamente com o EN2 (materiais provenientes de reciclagem), também um dos mais evidenciados, verifica-se a preocupação com a evidenciação dos materiais usados que derivam de processos de reciclagem. Para Fischer e Waquil (2009, p. 6), “[...]o setor industrial de base florestal, devido ao seu potencial de impacto ecológico, é alvo de pressão quanto à sustentabilidade ambiental da sua produção em diversos países". Nessa perspectiva, o último relatório do Conselho Europeu de Papel Reciclado European Recovered Paper Council - ERPC, criado em novembro de 2000 com o objetivo de acompanhar os progressos alcançados no cumprimento das metas de reciclagem estabelecidas na Declaração Europeia sobre Reciclagem de Papel, evidencia que a Europa alcançou nível recorde mundial em reciclagem de papel em 2009. A taxa chegou a 72,2\%, superior, portanto, à meta estabelecida em seu compromisso para 2010, de 66\%. O volume total reciclado em fábricas de papel chegou a 58 milhões de toneladas em 2009 (European Recovered Paper Council, 2011).

O bom desempenho das empresas da Espanha na evidenciação do indicador EN8, que diz respeito ao total de retiradas de água, por fonte, pode ser explicado pela legislação da União Europeia (2010), que estabelece um quadro comunitário para a proteção e a gestão da água, além da Convenção sobre Cooperação para a Proteção e o Aproveitamento Sustentável das Águas das Bacias Hidrográficas Luso-Espanholas, de 1998, que, no item 3 do artigo 15, assim dispõe: "as partes adotam medidas e ações tendentes à racionalização e economia do aproveitamento dos recursos hídricos e coordenam, através da Comissão, a permuta de informação sobre as respectivas experiências e perspectivas” (Resolução da Assembleia da República n. o 66/99, 1999).

Em relação aos indicadores ambientais menos evidenciados pelas empresas de ambos os países, tomando-se por base a evidenciação abaixo de $30 \%$, foram identificados os indicadores EN15, EN24, EN25 e EN27, conforme demonstrado na Tabela 2. Tais indicadores são muitos específicos, sendo que dois deles não se aplicam a todas as empresas (Adicionais). Para as empresas dos dois países, os indicadores menos evidenciados não divergem muito, com exceção do EN27, que no Brasil mostrou evidenciação acima de $30 \%$.

Revista de Gestão Social e Ambiental - RGSA, São Paulo, v. 7, n. 1, p. 35-52, jan./abr. 2013. 
Tabela 2 - Indicadores menos evidenciados pelas empresas no Brasil e na Espanha

\begin{tabular}{c|l|l|l|l}
\hline Cód. & Indicador & $\begin{array}{l}\text { Total } \\
\mathbf{\%}\end{array}$ & $\begin{array}{l}\text { Brasil } \\
\mathbf{\%}\end{array}$ & $\begin{array}{l}\text { Espanha } \\
\mathbf{\%}\end{array}$ \\
\hline EN15 & $\begin{array}{l}\text { Número de espécies na Lista Vermelha da IUCN e em listas nacionais de } \\
\text { conservação com habitats em áreas afetadas por operações, discriminadas } \\
\text { pelos respectivos níveis de risco de extinção }\end{array}$ & 20,7 & 21,8 & 19,9 \\
\hline EN24 & $\begin{array}{l}\text { Peso de resíduos transportados, importados, exportados ou tratados } \\
\text { considerados perigosos nos termos da Convenção da Basileia 13 e e } \\
\text { percentual de carregamento de resíduos transportados internacionalmente }\end{array}$ & 26,8 & 27,4 & 26,3 \\
\hline EN25 & $\begin{array}{l}\text { Identificação, tamanho, status de proteção e índice de biodiversidade de } \\
\text { corpos d’água e habitats significativamente afetados por descartes de água } \\
\text { e drenagem realizados pela organização relatora }\end{array}$ & 23,2 & 18,5 & 26,9 \\
\hline EN27 & $\begin{array}{l}\text { Percentual de produtos e suas embalagens recuperadas, em relação ao total } \\
\text { de produtos vendidos }\end{array}$ & 25,7 & 33,1 & 19,9 \\
\hline
\end{tabular}

Fonte: Dados da pesquisa

Para comparação das médias dos grupos, após a aplicação do teste Kolmogorov-Smirnov, por meio do qual se verificou que os dados não apresentam distribuição normal, foi utilizado o teste não-paramétrico de Mann-Whitney. Inicialmente, foi aplicado o teste em relação ao total dos indicadores evidenciados pelas empresas dos dois países. Assim, analisando-se os resultados do teste de médias, apresentados na Tabela 3, pode-se inferir que, em relação ao total de indicadores evidenciados, não há diferença significativa entre o grupo de empresas brasileiras e o grupo de empresas espanholas, rejeitando-se, portanto, a hipótese da pesquisa. Destaca-se que, apesar de a Espanha estar inserida em um marco regulatório superior ao brasileiro, as empresas brasileiras são proativas em termos de evidenciação ambiental, equiparando-se às espanholas, considerando-se os indicadores analisados.

Tabela 3 - Teste de médias - empresas brasileiras e espanholas

\begin{tabular}{l|l|l|l|l}
\hline Grupo de Indicadores & Média Brasil & Média Espanha & Diferença da Média & $\begin{array}{l}\text { Nível de } \\
\text { Significância }\end{array}$ \\
\hline Total de Indicadores & 14,782258 & 15,871795 & $-1,089537$ & 0,223 \\
\hline Materiais & 1,185484 & 1,519231 & $-0,333747$ & $0,001^{*}$ \\
\hline Energia & 2,741935 & 3,435897 & $-0,693962$ & $0,000^{*}$ \\
\hline Água & 1,540323 & 1,461538 & 0,078784 & 0,556 \\
\hline Biodiversidade & 2,080645 & 1,762821 & 0,317825 & 0,103 \\
\hline Emissões, efluentes e resíduos & 4,661290 & 5,070513 & $-0,409222$ & 0,259 \\
\hline Produtos e serviços & 1,016129 & 0,942308 & 0,073821 & 0,411 \\
\hline Conformidade legal & 0,612903 & 0,788462 & $-0,175558$ & $0,001^{*}$ \\
\hline Transporte & 0,370968 & 0,378205 & $-0,007237$ & 0,901 \\
\hline Geral & 0,572581 & 0,512821 & 0,059760 & 0,320 \\
\hline
\end{tabular}

Nota. $p^{*<. ~} 0,01$ (bi-tailed).

Fonte: Dados da pesquisa

Observando-se separadamente cada grupo de indicadores, foram encontradas diferenças significantes nos grupos Materiais, Energia e Conformidade legal. Nesses três grupos, a evidenciação das empresas espanholas é superior à das brasileiras. Esse resultado pode ser atribuído a algumas características da Comunidade Europeia, como, por exemplo, exigência de maior conformidade, preocupação energética, evidenciada no Relatório Geral sobre a atividade da União Europeia (União Europeia, 2010), e preocupação com a reciclagem dos materiais nas empresas (principalmente papel), como destacado anteriormente.

É importante ressaltar que se esperava um número maior de indicadores evidenciados pelas empresas espanholas, uma vez que essas empresas se encontram em maiores níveis de evidenciação, segundo a classificação do GRI, como mostra a Tabela 4. 
Tabela 4 - Número de empresas por nível de evidenciação do GRI

\begin{tabular}{|c|c|c|c|c|c|c|c|c|c|}
\hline \multicolumn{2}{|l|}{ País } & $A+$ & A & B+ & B & $\mathrm{C}+$ & C & $\begin{array}{l}\text { Não } \\
\text { declarado }\end{array}$ & Total \\
\hline \multirow{2}{*}{ Espanha } & $\mathrm{N}$ & 91 & 20 & 5 & 11 & 2 & 21 & 6 & 156 \\
\hline & $\%$ & 58,3 & 12,8 & 3,2 & 7,0 & 1,3 & 13,5 & 3,8 & 100,0 \\
\hline \multirow{2}{*}{ Brasil } & $\mathrm{N}$ & 20 & 13 & 8 & 26 & 4 & 31 & 22 & 124 \\
\hline & $\%$ & 16,1 & 10,5 & 6,4 & 21,0 & 3,2 & 25,0 & 17,7 & 100,0 \\
\hline \multirow{2}{*}{ Total } & $\mathrm{N}$ & 111 & 33 & 13 & 37 & 6 & 52 & 28 & 280 \\
\hline & $\%$ & 39,6 & 11,8 & 4,6 & 13,2 & 2,1 & 18,6 & 10,0 & 100,0 \\
\hline
\end{tabular}

Fonte: Dados da pesquisa

A análise do teste de médias das empresas dos dois países evidenciou que, apesar de possuir um número menor de empresas nos maiores níveis de evidenciação do GRI, o Brasil apresenta um desempenho de evidenciação ambiental similar ao da Espanha. Nesse sentido, julgou-se pertinente comparar também apenas as empresas brasileiras no maior nível de evidenciação do GRI com as empresas espanholas dessa mesma categoria. Essa análise possibilita verificar se as empresas brasileiras do nível A+ evidenciam de forma diferente, comparativamente às empresas espanholas do mesmo nível. O resultado do teste de médias, comparando-se apenas as empresas do nível A+ dos dois países, é apresentado na Tabela 5.

Tabela 5 - Teste de médias com as empresas do nível A+ do GRI

\begin{tabular}{l|l|l|l|l}
\hline Grupo de Indicadores & Média Brasil & Média Espanha & Diferença da Média & Nível de Significância \\
\hline Total de Indicadores & 23,300000 & 18,922222 & 4,377778 & $0,008^{*}$ \\
\hline Materiais & 1,950000 & 1,744444 & 0,205556 & $0,076^{*}$ \\
\hline Energia & 4,350000 & 3,666667 & 0,683333 & $0,073^{*}$ \\
\hline Água & 2,200000 & 1,677778 & 0,522222 & $0,033^{*}$ \\
\hline Biodiversidade & 3,650000 & 2,322222 & 1,327778 & $0,006^{*}$ \\
\hline Emissões, efluentes e resíduos & 7,150000 & 6,300000 & 0,850000 & 0,173 \\
\hline Produtos e serviços & 1,500000 & 1,066667 & 0,433333 & $0,006^{*}$ \\
\hline Conformidade legal & 0,900000 & 1,000000 & $-0,100000$ & $0,003^{*}$ \\
\hline Transporte & 0,700000 & 0,488889 & 0,211111 & 0,089 \\
\hline Geral & 0,900000 & 0,655556 & 0,244444 & $0,032^{*}$
\end{tabular}

Nota. $\mathrm{p}^{*<.05}$ (bi-tailed).

Fonte: Dados da pesquisa

A análise da Tabela 5 mostra que, em termos de Emissões, efluentes e resíduos e Transporte, Brasil e Espanha possuem indicadores semelhantes, não havendo diferença entre as empresas dos dois países nesses quesitos. Entretanto, em todos os outros indicadores o resultado do teste de médias indicou que as empresas brasileiras do nível $\mathrm{A}+$ evidenciam mais indicadores que as espanholas no mesmo nível.

Foi realizada também a comparação em termos de indicadores ambientais dos grupos Adicionais e Essenciais das empresas brasileiras e espanholas do nível A+ (Tabela 6). O resultado encontrado para o teste de médias aferiu que as empresas brasileiras do nível A+ estudadas apresentam mais indicadores do grupo Adicionais do que a Espanha, corroborando o resultado anterior. Assim, é possível concluir que as empresas brasileiras do nível A+ investigadas adotam mais indicadores ambientais que as espanholas do mesmo nível.

Tabela 6 - Teste de médias com indicadores Essenciais e Adicionais do Brasil e da Espanha

\begin{tabular}{l|l|l|l|l}
\hline Grupo de Indicadores & Média Brasil & Média Espanha & Diferença da Média & $\begin{array}{l}\text { Nível } \\
\text { Significância }\end{array}$ \\
\hline Indicadores Essenciais & 15,500000 & 13,666667 & 1,833333 &, 057 \\
\hline Indicadores Adicionais & 9,400000 & 6,400000 & 3,000000 &, $003^{*}$ \\
\hline
\end{tabular}

Nota. $p^{*<.05}$ (bi-tailed).

Fonte: Dados da pesquisa 
Essa proatividade ambiental brasileira, em termos de evidenciação ambiental superior à das empresas espanholas, pode ser explicada pela própria natureza das empresas A+ brasileiras. Das 20 empresas A+ brasileiras, cinco pertencem ao setor financeiro, que, segundo Crisóstomo, Freire e Vasconcellos (2011), é um dos mais atuantes e representativos em termos de responsabilidade social no Brasil; e sete empresas pertencem ao setor de energia elétrica, sofrendo forte regulação da Aneel, enquanto as 91 empresas A+ da Espanha estão distribuídas em diversos setores.

Apesar de o setor econômico ser uma variável que pode influenciar o nível de evidenciação de algumas empresas, isso não prejudicou a análise geral dos indicadores mais evidenciados, nem dos testes de médias aplicados, visto que foram analisados todos os níveis de evidenciação das 280 empresas da amostra, pertencentes aos mais diversos setores, segundo a classificação por setor do GRI. Segundo a GRI (2006), o modelo do relatório GRI possibilita a comparação entre empresas porque possui indicadores que se aplicam a qualquer uma delas, independentemente de sua atividade, tamanho e localidade.

\section{CONSIDERAÇÕES FINAIS}

Este artigo teve por objetivo comparar os indicadores ambientais utilizados pelas empresas brasileiras com aqueles utilizados pelas empresas espanholas, segundo o relatório Global Reporting Initiative (GRI), levando-se em conta que os sinais (indicadores ambientais) funcionam como mecanismos de discriminação. Para tanto, foram analisados os indicadores ambientais evidenciados por empresas brasileiras e espanholas nos seus relatórios de sustentabilidade de 2009, disponibilizados a partir de 2010 nos respectivos websites, verificando-se se a evidenciação ambiental desses indicadores pelas empresas brasileiras é diferente daquela apresentada pelas empresas espanholas.

Foi apurado que os indicadores mais evidenciados por ambos os países dizem respeito a Materiais, Energia, Água, Emissões, efluentes e resíduos, Produtos e serviços e Conformidade legal, enquanto os indicadores menos evidenciados são específicos, não se aplicando a todas as empresas. Identificou-se uma preocupação das empresas em evidenciar os indicadores do grupo Essenciais, embora a questão relacionada a emissões de gases causadores do efeito estufa (grupo Adicionais) tenha apresentado um alto nível de evidenciação, colocando a questão das mudanças climáticas como um risco eminente.

A análise comparativa das empresas dos dois países, realizada a partir do teste de médias, possibilitou inferir que, levando-se em conta o total de indicadores evidenciados, as empresas não apresentam diferenças significativas, implicando dizer que as empresas brasileiras e espanholas não apresentam similaridade em termos de total de indicadores evidenciados. Analisando-se os indicadores em grupos separados, foram encontradas diferenças significativas apenas nos grupos de indicadores Materiais, Energia e Conformidade legal, indicando que as empresas espanholas apresentam melhor nível de evidenciação sobre tais indicadores. Atribui-se esse diferencial à influência da regulamentação da Comunidade Europeia e da Espanha quanto aos aspectos relacionados a tais indicadores.

Foram analisadas ainda as empresas com maior nível de evidenciação (A+) do Brasil e da Espanha, segundo classificação da GRI, a fim de se confirmar se essas empresas também apresentavam resultados similares. Nesse caso, o teste de médias resultou em diferença significativa, favorecendo as empresas do Brasil. Com exceção de Emissões, efluentes e resíduos e Transporte, os indicadores apresentaram médias significativamente diferentes, indicando uma superioridade das empresas brasileiras. Foi verificado ainda que as empresas A+ brasileiras evidenciam mais indicadores do grupo Adicionais do que as empresas da Espanha. Destaca-se, nesse sentido, a boa performance das empresas brasileiras, inseridas num contexto de país emergente, quando comparadas às empresas da Espanha, considerada nação desenvolvida. Assim, pode-se afirmar que as empresas A+ brasileiras, em conformidade com a teoria da sinalização,

Revista de Gestão Social e Ambiental - RGSA, São Paulo, v. 7, n. 1, p. 35-52, jan./abr. 2013. 
apresentam sinais positivos em relação à questão ambiental, por meio dos indicadores ambientais evidenciados nos relatórios GRI analisados, diferenciando-se das empresas A+ da Espanha.

Sugere-se como futuros estudos no campo da sustentabilidade, em especial na temática ambiental, a aplicação de pesquisas qualitativas para analisar a qualidade das informações ambientais divulgadas nos relatórios de empresas de diferentes nacionalidades, com o intuito de se averiguar semelhanças e divergências quanto às práticas ambientais e às medidas de mensuração e monitoramento adotadas pelas empresas quanto aos indicadores GRI.

\section{REFERÊNCIAS}

Akerlof, G.A. (1970) The market for "lemons": quality uncertainty and the market mechanism. The Quarterly Journal of Economics, 84 (3), 488-500.

Anand, B.N., Shachar, R. (2007) (Noisy) communication. Quantitative Market Economics, 5, 211237.

Antonio, A., Neto. (2009) As influências dos tratados internacionais ambientais celebrados pelo Brasil no ordenamento jurídico brasileiro. Recuperado em: 28 maio, 2011, de <http://www.lfg.com.br>.

Barbieri, J. C. (2007) Gestão ambiental empresarial: conceitos, modelos e instrumentos (2 ed). São Paulo: Saraiva.

Barbieri, J. C., Cajazeira, J. E. R. (2009) Responsabilidade social empresarial e empresa sustentável: da teoria à prática. São Paulo: Saraiva.

BMF\&Bovespa. (2011) Índice de Sustentabilidade Empresarial - ISE- o que é o ISE? Recuperado em: 29 maio, 2011, de <http://www.bmfbovespa.com.br/indices/ResumoIndice.aspx ?Indice=ISE\&Idioma=pt-BR>.

Comissão das Comunidades Europeias. (2001). Promover um quadro europeu para a responsabilidade social das empresas. Recuperado em 28 maio, 2011, de http://eurlex.europa.eu/LexUriServ/site/pt/com/2001/com2001_0366pt01.pdf.

Comissão Europeia. (2010) O que é o Pacto de Autarcas?. Recuperado em 4 junho, 2011, de http://ec.europa.eu/portugal/comissao/destaques/20100427_pacto_autarcas_pt.htm.

Crisóstomo, V. L., Freire, F. S., Vasconcellos, F. C. (2011) Corporate social responsibility, firm value and financial performance in Brazil. Social Responsibility Journal, 7(2), 295-309.

Dancey, C.P., Reidy, J. (2006) Estatística sem matemática para psicologia: usando SPSS para Windows. Porto Alegre: Artmed.

Dewally, M., Ederington, L. (2006) Reputation, certification, warranties, and information as remedies for seller-buyer information asymmetries: lessons from the online comic cook market. Journal of Business, 79(2), 693-729.

Europa. (2000) Sínteses da legislação da UE Proteção e gestão da água. Recuperado em 5 junho, 2011, de: http://europa.eu/legislation_summaries/environment/water_protection_management/128002b_pt.ht $\mathrm{m}$. 
European Recovered Paper Council. (2011) Europe shows global leadership in recycling. Recuperado em 5 junho, 2011, de http://www.paperrecovery.org/newsmanager/41/79/Europeshows-global-leadership-in-recycling/.

Fávero, L. P. L., Belfiore, P. P., Chan, B. L., \& Silva, F. L. (2009) Análise de dados: modelagem multivariada para tomada de decisões. São Paulo: Campus.

Fischer, B.B., Waquil, P.D. (2009) Sistemas de certificação florestal no setor brasileiro de papel e celulose: influências no desempenho exportador. Revista de Economia Agrícola, 56(2), 5-19.

Gasparino, M. (2006) Análise de relatórios de sustentabilidade, com ênfase na GRI: comparação entre empresas do setor de papel e celulose dos Estados Unidos e Brasil.

Encontro da Associação Nacional de Pós-Graduação e Pesquisa em Administração, Salvador, Brasil, 30.

Global Reporting Initiative. (2006) Diretrizes para relatório de sustentabilidade. Recuperado em 20 abril, 2011, de http://www.globalreporting.org/NR/rdonlyres/4855C490-A872-49349E0B8C2502622576/5288/DiretrizesG3.pdf.

Global Reporting Initiative. (2009) Número de empresas no mundo todo que relata seu desempenho de sustentabilidade atinge recorde, mas é ainda minoria. Recuperado em 21 abril, 2011, de http://www.globalreporting.org/NewsEventsPress/PressResources/2009/Pressrelease_15_Jul_2009_ PT.htm.

Global Reporting Initiative. (2011) GRI reports list. Recuperado em 22 abril, 2011, de http://www.globalreporting.org/ReportServices/GRIReportsList.

Gonzalez-Benito, J., Gonzalez-Benito, O. (2006) A review of determinant factor of environmental proactivity. Business Strategy and the Environment, 15(1), 87-102.

Instituto Ethos. (2011a) Indicadores Ethos $3^{a}$ geração. Recuperado em 28 maio, 2011, de: http://www.ethos.org.br/docs/conceitos_praticas/indicadores/indicadores3g.

Instituto Ethos. (2011b) Home. Recuperado em 28 maio, 2011, de http://www1.ethos.org.br/EthosWeb/Default.aspx.

Kalra, A., Li, S. (2008) Signaling quality through specialization. Marketing Science, 27(2), 168-84.

Lash, J., Wellington, F. (2007) Competitive advantage on a warming planet. Harvard Business Review, 85(3), 94-102.

Lei Federal $n^{o}$ 9.605, de 12 de fevereiro de 1998. (1998). Dispõe sobre as sanções penais e administrativas derivadas de condutas e atividades lesivas ao meio ambiente, e dá outras providências. Brasília, DF. Recuperado em 6 de maio, 2011, de http://www.planalto.gov.br/ccivil_03/leis/L9605.htm.

Lei Federal $n^{\circ}$ 9.984, de 17 de julho de 2000. (2000a). Dispõe sobre a criação da Agência Nacional de Águas - ANA, entidade federal de implementação da Política Nacional de Recursos Hídricos e de coordenação do Sistema Nacional de Gerenciamento de Recursos Hídricos, e dá outras 
providências. Brasília, DF. Recuperado em 6 de maio, 2011, de http://www.planalto.gov.br/ccivil_03/leis/L9984.htm.

Lei $n^{o}$ 10.165, de 27 de dezembro de 2000. (2000) Altera a Lei ${ }^{\circ}$ 6.938, de 31 de agosto de 1981, que dispõe sobre a Política Nacional do Meio Ambiente, seus fins e mecanismos de formulação e aplicação, e dá outras providências. Brasília, DF. Recuperado em 6 maio, 2011, de http://www.planalto.gov.br/ccivil_03/Leis/L10165.htm.

Lei Federal $n^{o}$ 12.305, de 02 de agosto de 2010. Institui a Política Nacional de Resíduos Sólidos; altera a Lei $\mathrm{n}^{\circ}$ 9.605, de 12 de fevereiro de 1998; e dá outras providências. Brasília, DF. Recuperado em 6 de maio, 2011, de http://www.planalto.gov.br/ccivil_03/_ato2007-2010/2010/lei/112305.htm.

Ley 4/2009 de 14 de mayo de 2009. (2009) Protección ambiental integrada. Recuperado em 28 maio, 2011, de https://www.derecho.com/l/boe/ley-4-2009-proteccion-ambiental-integrada.

Lins, L. S., \& Silva, R. N. S. (2009) Responsabilidade socioambiental ou Greenwash: uma avaliação com base nos relatórios de sustentabilidade ambiental. Revista Sociedade, Contabilidade e Gestão, 4(1), 91-105.

Lores, R. J. (2002) Como ficar rico: entrevista com José María Aznar. Recuperado em 2 julho, 2011, de http://veja.abril.com.br/041202/entrevista.html.

Maia, N.B., Martos, H.L., Barrela, W. (Org). (2001) Indicadores ambientais: conceitos $e$ aplicações. São Paulo: PUC.

Nossa, V., Cezar, J. F., Silva, A., Jr., Baptista, E. C. S., \& Nossa, S. N. (2009) Relação entre o retorno anormal e a responsabilidade social e ambiental: um estudo empírico na Bovespa no período de 1999 a 2006. Brazilian Business Review, 6(2), 121- 136.

Oliveira, J. A. P. (2008) Empresas na sociedade: sustentabilidade e responsabilidade social. Rio de Janeiro: Elsevier.

Organisation for Economic Co-operation and Development. (2007) Relatório sobre a reforma regulatória: Brasil fortalecendo a governança para o crescimento. Recuperado em 2 julho, 2011, de http://www.direitodoestado.com/palestras/BRASIL\%20$\% 20$ fortalecendo\%20a\%20governanca\%20para\%20o\%20crescimento.pdf.

Resolução ANEEL $n^{\circ}$ 456, de 29 de novembro de 2000. (2000b) Estabelece, de forma atualizada e consolidada, as Condições Gerais de Fornecimento de Energia Elétrica. Recuperado em 5 maio, 2011, de http://www.aneel.gov.br/cedoc/bres2000456.pdf.

Resolução da Assembleia da República n. ${ }^{\circ}$ 66/99. (1999) Aprova, para ratificação, a Convenção sobre Cooperação para a Proteção e o Aproveitamento Sustentável das Águas das Bacias Hidrográficas Luso-Espanholas e o Protocolo Adicional. Recuperado em 5 junho, 2011, de http://snirh.pt/index.php?idMain=6\&idItem=1.

Resolução CFC $n^{o}$ 1.003/2004. (2004) Dispõe sobre informações de natureza social e ambiental. $\begin{array}{lllll}\text { Recuperado em } & 20 & \text { maio, }\end{array}$ http://www.cfc.org.br/sisweb/sre/detalhes_sre.aspx?Codigo=2004/001003.

Richardson, R. J. (2008) Pesquisa social: métodos e técnicas (3. ed.). São Paulo: Atlas. 
Spence, A. M. (1973) Job market signaling. The Quarterly Journal of Economics, 87(3), 355-374.

União Europeia. (2010) Relatório geral sobre a atividade da União Europeia 2010. Recuperado em 3 junho, 2011, de: http://europa.eu/generalreport/index_pt.htm.

Vieira, N. R. (2009) Poluição do ar: indicadores ambientais. Rio de Janeiro: Serviço Editoriais Ltda.

Willis, A. C. A. (2003) The role of the global reporting initiative's sustainability reporting guidelines in the social screening of investments. Journal of Business Ethics, 43, 233-237.

Data da submissão: 04/05/2012

Data da publicação: 30/04/2013 